\title{
Correction to: Dance and the Arts in Mexico, 1920-1950
}

\section{Correction to:}

The Author(s) 2018

E. Guerrero, Dance and the Arts in Mexico, 1920-1950, https://doi.org/10.1007/978-3-319-92474-8

The original version of this book was revised. The source for fig 3.2 and FM has been changed to Archivo General de la Nación.

The updated original online version for this chapter can be found at https://doi.org/10.1007/978-3-319-92474-8 https://doi.org/10.1007/978-3-319-92474-8_3 